\title{
Erratum to: Postvolcanic Aerosols: Measurements of Altitude and Particle Sizes with Twilight-Sky Polarimetry
}

\author{
O. S. Ugolnikov ${ }^{a, *}$ and I. A. Maslov ${ }^{a, * *}$ \\ ${ }^{a}$ Space Research Institute, Russian Academy of Sciences, Moscow, 117997 Russia \\ *e-mail: ougolnikov@gmail.com \\ **e-mail:imaslov@iki.rssi.ru
}

Received June 15, 2021; revised June 16, 2021; accepted June 17, 2021

DOI: $10.1134 / \mathrm{S} 0010952521110010$

The article "Postvolcanic Aerosols: Measurements of Altitude and Particle Sizes with Twilight-Sky Polarimetry," written by O. S. Ugolnikov and I. A. Maslov, was originally published electronically in SpringerLink on April 5, 2021 without Open Access. After publication in volume 59, issue 2, pages 111-117 the authors decided to make the article an Open Access publication. Therefore, the copyright of the article has been changed to (C) The Author(s) 2021 and the article is forthwith distributed under the terms of a Creative
Commons Attribution 4.0 International License (http://creativecommons.org/licenses/by/4.0/, CC BY), which permits use, duplication, adaptation, distribution and reproduction of a work in any medium or format, as long as you cite the original author(s) and publication source, provide a link to the Creative Commons license, and indicate if changes were made.

The original article can be found online at https://doi.org/10.1134/S0010952521020076 